\title{
A NOTE ON NUMERICAL RADIUS AND THE KREIN-LIN INEQUALITY
}

\author{
SILVESTRU SEVER DRAGOMIR
}

\begin{abstract}
In this note we show that the KreĬn-Lin triangle inequality can be naturally applied to obtain an elegant reverse for a classical numerical radius power inequality for bounded linear operators on complex Hilbert spaces, due to C. Pearcy.
\end{abstract}

MSC 2010. 47A63.

Key words. Triangle inequality, operator norm, numerical radius.

\section{REFERENCES}

[1] S.S. Dragomir, Some Grüss type inequalities in inner product spaces, JIPAM, 4 (2003), $1-10$.

[2] S.S. Dragomir, Inequalities for the numerical radius of linear operators in Hilbert spaces, Springer Briefs in Mathematics, Springer, Cham, 2013.

[3] K.E. Gustafson and D.K.M. Rao, Numerical range, Springer-Verlag, New York, 1997.

[4] P.R. Halmos, A Hilbert space problem book (second edition), Springer-Verlag, New York, 1982.

[5] M.K. Kreĭn, Angular localization of the spectrum of a multiplicative integral in a Hilbert space, Funct. Anal. Appl., 3 (1969), 89-90.

[6] M. Lin, Remarks on Krein's inequality, Math. Intelligencer, 34 (2012), 3-4.

[7] C. Pearcy, An elementary proof of the power inequality for the numerical radius, Michigan Math. J., 13 (1966), 289-291.

Received March 13, 2018

Accepted May 22, 2018

\author{
Victoria University \\ Mathematics, College of Engineering \& Science \\ PO Box 14428 \\ Melbourne City, MC 8001, Australia \\ E-mail: sever.dragomir@vu.edu.au
}

The author thanks the referee for his helpful comments and suggestions.

DOI: $10.24193 /$ mathcluj.2018.2.06 